\title{
STRUCTURAL AND MOLECULAR DETERMINATION OF A ZINC COMPLEX WITH SCHIFF BASE
}

Santos, S. F. F. ${ }^{*}$; Wegermann, C. A. ${ }^{2}$; Monsalve ${ }^{1}$, M. S.; Simone, C. A. ${ }^{3}$; Ferreira, A. M. C. ${ }^{2}$; Santos, R. H. A. ${ }^{1}$

${ }^{1}$ USP-IQSC, University of São Paulo, São Carlos, SP, Brasil.

${ }^{2}$ USP-IQ, University of São Paulo, São Paulo, SP, Brasil.

${ }^{3}$ USP-IFSC, University of São Paulo, São Carlos, SP, Brasil.

*sinara@iqsc.usp.br

In recent years, it has been noticed an increase in the number of researches about the transition metal complexes with Schiff base because it's interesting structures and wide applications, due the formation of stable complexes, showing an important role in coordination chemistry. In this paper the complex was structurally characterized by X-ray diffraction (XRD) at $293 \mathrm{~K}$, using a single crystal with dimensions $0.08 \times 0.01 \times 0.3 \mathrm{~mm}$. To collect the intensities was used the $\operatorname{MoK} \boldsymbol{\alpha}(\lambda=0.71073 \AA)$ radiation.

The structure of $[\mathrm{Zn}(\mathrm{C} 14 \mathrm{H} 13 \mathrm{~N} 3)](\mathrm{ClO} 4) 2.0 .5(\mathrm{H} 2 \mathrm{O})$ shows that the compound belongs to orthorhombic system; space group Pbcn. The crystallographic parameters are: $\mathrm{a}=15.7765$ (5) $\AA, \mathrm{b}=14.0793$ (4) $\AA, \mathrm{c}=15.8708$ (5) $\AA, Z=4$ molecules / unit cell, $V=3525.26(19) \AA^{3}$ and $F(000)=1523$ the resolution of the structure was carried out by direct methods using the WingX1 program SHELX 972 and the model was refined by least-squares on F2 using full matrix. The central atom zinc has bipyramidal geometry bounded to 6 nitrogen atoms. The molecular arrangement by discrete molecules since the $\mathrm{Zn}$ atom is in a special position. The water molecule of crystallisation is disordered in two positions adding approximately 0.5 as total occupation factor. The final model showed an index of disagreement $\mathrm{R} 1=0.0696, \mathrm{Rw}=0.2341$ and $\mathrm{S}=1.06$. The results of interatomic distances and angles were obtained by PLATON3 and it is in conformity with the normal and expected values. 